\title{
Da argumentação à demonstração: os estreitamentos focais como estratégias de objetivação
}

\section{Rui Alexandre Grácio}

Doutor em Comunicação pela Universidade do Minho (UM), Portugal. rgracio@gmail.com

Resumo: Partindo da ideia de que a afirmação da objetividade é sempre produto de estratégias de objetivação, propõe-se neste texto caracterizar e assinalar a importância dos "estreitamentos focais" como um tipo de estratégia argumentativa mas, também, como uma forma de exercício de poder. Por outro lado - e à luz da noção de "estreitamento focal" - retomaremos a questão da articulação entre argumentação e demonstração, focando-nos na forma como acontece a construção argumentativa da demonstração. A interrogação final incide sobre o significado e as consequências sociais da valorização pragmática do demonstrativo enquanto dispositivo de poder e dominação.

Palavras-chave: Estreitamentos focais. Estratégias de objetivação. Argumentação. Demonstração.

Abstract: Starting from the idea that the affirmation of objectivity is always the product of objectivation strategies, it is proposed in this text to characterize and point out the importance of "focal narrowing" as a type of argumentative strategy, but also as a form of exercise of power. On the other hand - and in the light of the notion of "focal narrowing" - we will return to the question of the articulation between argumentation and demonstration, focusing on how the argumentative construction of the demonstration takes place. The final interrogation focuses on the meaning and social consequences of the pragmatic valuation of the statement as a device of power and domination.

Keywords: Focal narrowing. Objectification strategies. Argumentation. Demonstration. 
Introdução

"É também possível que a ideia de argumentação tenha sido
descartada nas épocas da monarquia, do poder absoluto e da
ditadura. [...] Cada vez que chegamos a regimes monolíticos
vemos que se gosta das verdades evidentes, das deduções
retilíneas e não muito do pró e do contra, da argumentação"

(Perelman, 1970, p. 320, tradução minha)

Comecemos esta exposição com a elucidação da expressão "estratégias de objetivação” que faz parte do título. O que pretendemos realçar com a sua utilização? Com ela queremos salientar que a objetividade nunca é algo de dado, nem representa um qualquer desvelamento da realidade tal qual ela é.

A este mito do originário e de uma realidade primeira, passível de ser desvelada na sua essência, esteve subjacente uma determinada filosofia do sujeito, de um sujeito que, com a visão da sua intuição evidente, teria a capacidade de aceder diretamente "às coisas mesmas".

Contudo, muitos filósofos mostraram, contra a teoria correspondencialista da verdade, que o nosso acesso à realidade é sempre mediado, seja por estruturas a priori do sujeito, como defendia Kant, seja pelo uso da linguagem que, com as sua possibilidade de nomear, discriminar e sequenciar, acaba por repercutir modos culturais de perspetivar, conceber, percepcionar ou se posicionar no mundo.

Assim, quando falo em estratégias de objetivação, aquilo que pretendo assinalar é que qualquer tipo de objetividade que queiramos afirmar é sempre um resultado, ou um efeito do discurso, efeito que decorre da forma como no discurso se gere o campo do pressuposicional ${ }^{1}$. Dito de outra maneira, todo o discurso é intrinsecamente estratégico porque implica (consciente ou inconsciente, voluntária ou involuntariamente, pouco importa) a assunção de pressupostos.

$E$, no entanto, quando falamos de objetividade, tendemos a encará-la ou como sendo algo que corresponde à natureza das coisas (sem nada pressupor, por conseguinte, um velho ideal filosófico) ou como algo que é objeto de um acordo universal ( $\mathrm{e}$, neste caso, neutraliza-se a dimensão intrinsecamente perspetivada dos pressupostos, passando estes a surgir como uma realidade natural, inquestionada e tautológica - as coisas são o que

\footnotetext{
${ }^{1}$ Ou seja, que tem a ver com a seleção daquilo que fica implícito, inquestionado e eventualmente inquestionável e aquilo que é explícito, objeto de controvérsia e questionável.
} 
são). É como se, para instaurar a objetividade, fosse preciso dar-se uma ruptura entre o que é objetivo e o que é fruto de estratégia.

No entanto, e essa é uma tese que aqui defenderei, não ignorar a importância das mediações significa que toda a objetividade resulta, ou é um efeito, de vias de acesso a modos de ver que não excluem outras possibilidades. A objetividade não se deve contrapor nem ao pluralismo, nem ao perspetivismo, mas isso só é possível se a encararmos de um modo retórico. Vejamos isto mais de perto.

\section{Mediação, objetividade e objetivação}

Partindo da ideia de que os instrumentos de mediação estão intimamente ligados aos modos de descrever e de objetivar a realidade (assim, podemos perguntar, de um modo abrangente, 'com que meios e sem que meios o fazemos?' ou, de uma perspetiva mais apertada e restringida ao plano discursivo, 'com que palavras e sem que palavras, filtrando e salientado que aspetos?'), encaramos a objetividade como fruto de estratégias de objetivação que adquirem força e poder no interior de dinâmicas sociais de construção da realidade conducentes, nomeadamente, a legitimar os discursos oficiais e a fundamentar decisões institucionais.

Hoje em dia, por exemplo nos tribunais, é comum associar-se, no que diz respeito a decisões institucionais, a objetividade à imparcialidade e à justiça, e a ausência de objetividade à parcialidade e à descrença na aplicação do direito.

Por conseguinte, o requisito da objetividade surge, em diferentes práticas sociais, como uma exigência, e um marco, que de alguma forma permite passar do discutível ao indiscutido, que possibilita o trânsito da argumentação para a demonstração, ou seja, que conduz à consideração de algo como provado, aceite, fora de questão, para lá de qualquer dúvida razoável e, por isso, base segura e certa para tomadas de decisão.

Pela nossa parte, defendemos que essa passagem opera com base num estreitamento focal $^{2}$ e iremos explicitar esta noção não só como uma estratégia argumentativa mas, também, como uma forma de exercício de poder.

\footnotetext{
${ }^{2}$ Conferir Grácio (2013, p. 73-74).
} 


\section{$\mathrm{El} \square \mathrm{dA}$}

2. Campos de argumentação, diferenciação funcional e lógica do poder

As questões de poder estão sempre ligadas ao exercício de uma autoridade discricionária que determina não só o que é, ou não, relevante na abordagem de dados assuntos em questão como, de uma forma mais ampla, institui os tipos de questões passíveis de serem tratadas dentro de um campo delimitado pela sua lógica, regras práticas e linguagem próprias.

Ou seja, a sociedade funciona segundo diferenciações funcionais instituídas (diferentes 'áreas de problemáticas' com suas regulamentações, poderíamos dizer) destinadas a acolher o tratamento de determinados assuntos nos seus próprios termos, sendo que destes termos faz parte um sistema com uma lógica, uma linguagem e um conjunto de regras e procedimentos que permitem, em princípio, decidir objetivamente. Dito ainda de outra forma, os sistemas sociais diferenciados funcionalmente estão idealmente aptos a produzirem respostas-decisão para cada caso problemático específico avaliado nos padrões da sua autoreferencialidade.

Correspondendo a esta ideia de que a argumentação em torno de decisões práticas, e ocorrendo no interior de práticas sociais institucionais, está sempre condicionada pelos poderes instituídos, pelos seus critérios de validade e pelo seu poder de impor respostas legítimas e de fazer valer, na prática, decisões, forjou-se o conceito de "campos de argumentação" e difundiu-se a ideia de que argumentar eficazmente implica entrar num determinado campo, conhecer a sua linguagem, submeter-se às regras do jogo e utilizá-las segundo a lógica e os procedimentos locais.

A sociedade organizada por diferenciação funcional é assim, em última análise, solidária de uma lógica da especialização cujo domínio ditaria a competência argumentativa, o discurso apropriado e a legitimidade discursiva.

O mesmo acontece com os discursos informais que, apesar de parecerem mais libertos de coerções institucionais, não deixam de ser alvo de constrangimentos sociais provenientes da doxa e, se não da ideologia dominante, pelo menos de ideias gerais transformadas em lugares comuns e, por conseguinte, de aceitação social tácita.

\section{Os constrangimentos das argumentações}

Com efeito, o poder do discurso extravasa sempre a sua dimensão estritamente linguística, e a conjugação articulada do ethos, de pathos e do 
logos, de matriz retórica, é preciosa para situarmos a força do discurso nos contextos multidimensionais de que ela depende.

Assim, perguntas como: quem é que fala? Em que contexto? A que título? Para que auditório? Em que situação? Com que finalidade? - são essenciais para a compreensão, quer do discurso, quer das argumentações (sendo que nestas últimas é também fundamental a questão de saber quem são os intervenientes, ou seja, quem é que está a interagir com quem numa situação de desacordo).

Em suma, podemos dizer que a argumentação nunca está isenta de constrangimentos. Quando estamos num plano institucional, os aparelhos ideológicos do Estado, secundados pelas forças repressivas, fazem valer os termos da admissibilidade em que o falar - e o argumentar - podem ocorrer (ou seja, asseguram a legitimidade discursiva).

No plano das relações sociais informais, há toda uma pressão para a conformidade, para o que é considerado como "normal", para o senso comum ou para o que é naturalizado pela influência das agendas mediáticas, assomando aqui a ideia de um auditório universal patente em expressões como "a ninguém passará pela cabeça" ou "todos concordarão que" ou em juízos como "é intolerável” ou “é inadmissível”.

\section{Estreitamentos focais, discurso e a presença do poder nas relações sociais}

Mas, voltemos à temática da objetivação, da produção de objetividade através de estreitamentos focais, ou, dito de outro modo, à construção argumentativa da demonstração ${ }^{3}$.

Há toda uma tradição académica que insiste, e bem, em diferenciar a argumentação da demonstração. Menos frequente é o que aqui propomos averiguar (partindo da ideia de que a argumentação é mais ampla que a demonstração), a saber, como é que se processa a articulação entre argumentação e demonstração e, mais ainda, em que medida é que a construção argumentativa da demonstração é instituinte de formas práticas de poder.

Coloquemos o assunto que nos move em termos filosóficos. Uma das prováveis razões teóricas da presença irredutível da argumentação nas nossas vidas reside em dois factos: o primeiro é que nem tudo se pode definir (ideia

\footnotetext{
${ }^{3}$ Conferir Plantin (2016, p. 472-473) e Grácio (2013, p. 61, 66).
} 
que aliás é reconhecida pela lógica, que parte de pontos de partida - sejam estes premissas, postulados, axiomas, regras, etc. - que aceita como tais e a partir dos quais desenvolve inferências e raciocínios segundo regras dadas); o segundo é que as definições totalmente formalizadas tornam-se excessivamente abstratas e vazias, perdendo aderência aos casos concretos, com suas particularidades e especificidades, e levantam o problema da aplicação.

Podemos mesmo dizer que quanto maior são os níveis de formalização, maior é a dificuldade em tornar evidente a aplicação de definições e de regras a casos concretos. Dito de outra forma, maior é a zona cinzenta e as possibilidades de interpretações diferentes.

É por isso uma questão fundamental - e note-se, uma questão fundamental de natureza moral, na qual a marca da responsabilidade subjetiva é incontornável - compreender como se operam as articulações entre o plano formal das definições e o plano pragmático das decisões fundamentadas e da ação justificada nas quais supostamente se estão a usar definições e a aplicar regras gerais a casos concretos.

Ora, é aqui que entram os procedimentos de estreitamento focal, por um lado, e a força dos sistemas instituídos, por outro.

Assim, para voltar ao exemplo anterior, é porque o sistema jurídico tem uma força instituída - seja através da existência de locais, agentes e procedimentos específicos, seja através de aparelhos repressivos que, em última instância, garantem, pelo uso da violência, simbólica ou física, a sua autoridade - que os estreitamentos focais podem ser impostos a quem entra nesse sistema.

Sendo o sistema jurídico um sistema de juízo e de decisão, ele muniu-se dos meios de dar respostas, introduzindo desde logo códigos procedimentais e de conduta e definindo os termos em que as questões podem ser abordadas. Dito de outro modo, os sistemas instituídos unilateralizam a comunicação ao imporem os termos, com suas possibilidades e limites, em que os assuntos em questão são passíveis de ser abordados.

Assim, como é sabido, o estreitamento focal operado nas práticas dos tribunais elege, como aquilo que numa primeira etapa é realmente relevante, as questões de facto.

Com isso, pode desde logo filtrar o discurso e atribuir irrelevância ao que nada tem a ver com o estabelecimento de factos. Ou seja, o discurso torna-se 
objeto de uma regulação discricionária que o pode classificar como autorizado e válido ou como inapropriado e irrelevante.

Numa segunda etapa, e após o apuramento dos factos, o estreitamento focal dá-se em torno das questões de direito, ou seja, da produção de uma sentença em que a lei seja aplicada, sendo que esta sentença tem sempre de ser sancionada pelo juiz que, em última análise, representa no tribunal a ordem do sistema jurídico.

Em suma: o procedimento designado como "estreitamento focal" está, no que diz respeito a tomadas de decisões com força de lei, indissociavelmente ligado aos poderes instituídos.

Os estreitamentos focais operam, no plano macro, por delimitação do perguntável em função das respostas que, enquanto sistema, estão preparados para dar, demarcam-se de tudo que não seja da ordem do próprio sistema, outorgam-se o poder discricionário de decidir o que é ou não relevante e escoram-se nas capacidades impositivas de que os sistemas socialmente autorizados gozam.

Os estreitamentos focais tendem, assim, para uma naturalização do pressuposicional que, subtraído ao questionamento, se apresenta como um suposto consenso despersonalizado e, por isso, merecedor da classificação de "objetivo".

Mas, porque é que este procedimento é importante para o estudo da argumentação?

Em primeiro lugar, ele conduz a abandonar as visões idealizadas das situações argumentativas como situações de suposta paridade. De facto, quando pensamos numa interação argumentativa entre duas pessoas consideradas abstratamente, tendemos a vê-la fora de contextos, papéis e sistemas sociais mais amplos, de sistemas que já carregam em si formas de poder e de dominação patentes na sua capacidade de unilateralizar os termos em que o perguntar e o responder podem ocorrer, na capacidade instituir procedimentos de objetivação e determinar condições de objetividade e, por tudo isso, que detêm não só a capacidade de impor toda uma série de restrições e limitações à circulação social dos discursos como tendem, ainda, a naturalizar a relação de submissão pré-formatada pelo próprio funcionamento do sistema.

Os estreitamentos focais são solidários da moldura ou enquadramento dos assuntos. Com efeito, se perguntarmos como é que são ditados os 
enquadramentos considerados como socialmente apropriados para o tratamento dos assuntos em questão, temos de responder que eles derivam do funcionamento de sistemas sociais estruturados e estruturantes que legitimam determinadas práticas.

Os estreitamentos focais, por seu turno, produzem as distinções - feitas sobretudo em torno do par relevante-irrelevante - que tornam o discurso consonante com esses enquadramentos legítimos.

Fugir ao enquadramento e ao estreitamento focal que dita o discurso como apropriado conduz frequentemente à desclassificação de quem assim procede e retira-lhe o "merecimento" de ser ouvido. Essa é aliás uma das funções dos estreitamentos focais: incluir quem alinha e excluir quem não alinha, correspondendo aqui a exclusão a uma filtragem que, criando uma indisposição para ouvir, tende a anular ou a diminuir o poder da palavra, ou do discurso, dissidente. Esta "anulação" pode ter níveis de eficácia e duração muito variáveis e é sabido que grandes transformações no que diz respeito a certas causas políticas transitaram de uma materialidade da repressão discursiva e de um ostracismo ideológico iniciais para um ponto de chegada em que o discurso repudiado acabou por ser integrado positivamente na doxa. Pensemos na escravatura, nos direitos da mulher, na segregação racial ou na questão das alterações climáticas.

Servem estes exemplos para dizer que os enquadramentos a partir dos quais pensamos e avaliamos não são eternos ou inalteráveis. Eles derivam de processos sociais e estão sujeitos aos movimentos de transformação social.

Do mesmo modo, os estreitamentos focais instituídos - espécie de braços discursivos que preservam os termos em que as questões devem ser colocadas - podem deixar de ter força quando perdem a adesão de uma comunidade que luta por horizontes axiologicamente mais alargados, plurais, humanos e justos.

Quando, precisamente, queremos participar na formulação das questões e não apenas receber respostas para perguntas que não fizemos. Quando a normativização e as quadrículas dos sistemas funcionais se tornam sufocantes, ameaçando a liberdade.

Com efeito, a partilha e a participação em assuntos em questão - com a necessidade de lidar com o controverso e com o plural que implica - está do lado da luta contra a heteronomia, da vigilância aos unanimismos suspeitos, da vinculação a causas, em suma, da coragem cidadã, enquanto a passividade 


\section{$\mathrm{EI} \square \mathrm{dA}$}

Revista Eletrônica de Estudos Integrados em Discurso e Argumentação, Ilhéus, n. 18, abr.2019.

e a docilidade da obediência daqueles que apenas querem respostas está do lado da dormência cobarde, da apatia e da vida omissa, servil e sem afirmação.

\section{Os estreitamentos focais e a construção argumentativa da demonstração}

Vejamos agora, mais de perto, os mecanismos da construção argumentativa da demonstração e a sua articulação com os estreitamentos focais.

Como anteriormente dissemos, e agora retomamos em termos mais genéricos, a argumentação é, por princípio, o terreno do discutível, sendo que deste faz parte a própria possibilidade de discutir os termos em que se colocam as questões.

É todavia evidente que estar a discutir em permanência os termos das questões é uma impossibilidade prática, ou seja, não funciona quando o propósito é produzir decisões e agir. Por outro lado, é também evidente que não é possível sair do plano das possibilidades infinitas sem operar estreitamentos focais que tornem razoáveis e aceitáveis as respostas-decisão.

Importa aliás reiterar - uma vez que estou apenas a tentar descrever um procedimento e não a avaliá-lo - que os estreitamentos focais são indispensáveis de um ponto de vista da vida prática e são recorrentemente requeridos como fundamentação da ordem, das decisões e das ações. No entanto, entre os dois polos extremos desta equação - a necessidade e a arbitrariedade, a solidez e a liquidez - há todo uma campo intermédio de modelagens possíveis que permitem a respiração da liberdade.

A questão que importa colocar é, por conseguinte, a de saber como é que se passa do discutível para o indiscutido (não se devendo confundir o indiscutido com indiscutível) e como é que esta passagem pode surgir como razoável.

O preceito de que aqui partimos é o de que devemos estar atentos às exigências que a ação, e a necessidade de decisão, exercem sobre o pensamento. Tomar decisões significa fazer escolhas ou propor caminhos, optar por determinadas vias (enquadramentos), em detrimento de outras. Dito de outra forma, nunca saímos do plano do questionamento para o das respostas sem sermos seletivos.

Ao selecionarmos certos aspetos em detrimento de outros (uns serão tomados por adquiridos e outros serão descartados) estamos desde logo a 
por em ação procedimentos de saliência e de filtragem, procedimentos que são a forma mais "invisível” dos estreitamentos focais.

Trata-se, no fundo, de assumir pressupostos sem que se tenha de dizer ou mesmo ter consciência de que eles são pressupostos. No entanto, no plano verbal e discursivo, estes implícitos pressuposicionais servirão para orientar (através do se... então...) o fio do discurso e tornar logicamente expectáveis certos tipos de raciocínios.

Expressões como "a nossa questão" ou "como é sabido" tendem geralmente a assumir que estamos a partir de pressupostos partilhados e que estes irão permanecer indiscutidos. É claro que isso pode não acontecer, mas a ideia é esses pontos de partida sejam tacitamente comungados e fiquem por isso inquestionados, permitindo decidir.

Este movimento de "colocar fora de questão" é mais explícito e menos problemático nos casos em que se pretende apresentar um saber como demonstrativo, uma vez que, nesses casos, a vantagem da resposta-certeza (ou solução, diferente de resposta) leva a considerar como uma conquista todas as etapas de formalização e de descarte do alternativo que possam impedir o carácter necessário da conclusão.

Na demonstração o 'terceiro excluído' e, de uma forma mais geral, a exclusão de hipóteses, é uma regra de progressão e um requisito para alcançar a certeza.

Ora, como não é ainda trivial sabermos lidar a falência dos absolutos, continuamos a fazer da certeza o nosso almejado ponto de ancoragem e persistimos na veneração da cientificidade e do seu ideal demonstrativo, ignorando que o progresso da ciência assenta numa especialização majorante que tem no seu reverso o caos dos espartilhos disciplinares para a qual não há respostas científicas.

Assim, e para concluir, a construção argumentativa da demonstração implica uma progressiva redução do que é discutível, uma delimitação do questionável e dos termos nos quais as perguntas podem ser colocadas, procedimentos de saliência e de filtragem e, finalmente, acordos sobre a linguagem adequada e sobre os procedimentos resolutivos solidários de um "colocar fora de questão" em prol da obtenção da certeza objetiva da resposta. Este conjunto de procedimentos produzem justamente aquilo que designámos como "estreitamentos focais". 
Eles operam tanto ao nível da explicação e dominação científica do mundo como no da compreensão e dominação prática das relações com o outro. O demonstrativo tem o seu equivalente social no que é obrigatório (por lei, ou por regra).

A sua importância é por isso fundamental e julgamos que a consciência dos mecanismos presentes nos estreitamentos focais pode contribuir para uma atitude mais crítica perante hegemonias discursivas que tendem a desacreditar a possibilidade do alternativo e da alternativa, a paralisar iniciativas ou movimentos de transformação e a perpetuar sistemas de exclusão.

Continuamos a ver o alternativo segundo a lógica dos princípios da contradição e do terceiro excluído e, sedentos de respostas certas, a tendência é a de reduzir o possível à solução única e não a modos múltiplos de perspetivar que entre si conflituam e disputam o lugar de valor de entrada.

Ora é esta mentalidade assente numa concepção acanhada da racionalidade, para glosar Perelman, que é preciso questionar e modificar.

Tarefa que não é, contudo, fácil de realizar no mundo atual, no qual os valores da cidadania se viram progressivamente substituídos pelos do consumismo, as competências de cidadão pelos desempenhos de consumidor e onde a máxima kantiana segundo a qual "as coisas têm preço, mas as pessoas têm dignidade" parece ter-se sido desacreditada e reduzida a uma mera fachada do politicamente correto atrás da qual se oculta a ideia generalizada de que tudo têm um preço.

Por outro lado, é também importante referir que a invasão das mediações tecnológicas é, paradoxalmente, solidária de processos de unilateralização da comunicação, os quais tendem a enfraquecer as possibilidades da proximidade dialógica da linguagem e a produzir comunicação sem conversação, na qual o fator empático - e marcadamente humano - tende a dissipar-se em detrimento do instrumental.

Este é um ponto de monta, pois apregoar os benefícios de uma racionalidade argumentativa numa sociedade de meios sem fins pode significar cair numa idealização que abstrai indevidamente do poder de penetração de um tal ideal de coexistência humana relativamente ao esteio material das práticas sociais reais que são suas condições de possibilidade.

De qualquer forma, e para finalizar com a ideia geral, penso que dessacralizar o demonstrativo em detrimento das possibilidades abertas pelo 


\section{EIDळA}

Revista Eletrônica de Estudos Integrados em Discurso e Argumentação, Ilhéus, n. 18, abr.2019.

questionamento plural, inerente ao plano argumentativo, é um momento importante, por um lado, para pensar, não apenas nas vantagens, mas também os custos humanos e sociais de um pensamento que aceita ser redutor para alcançar a ordem das certezas e o poder de controlo e, por outro, para manter em aberto a luta sempre inacabada por horizontes mais alargados de uma liberdade aferida não apenas como poder de escolha (opção pelo que nos é dado escolher) mas, de uma forma mais fundamental, encarada em termos do problema da livre iniciativa e da possibilidade do alternativo dissensual (diferendo).

\section{Referências}

GRÁCIO, Rui Alexandre. Vocabulário Crítico de Argumentação. Coimbra: Grácio Editor, 2013.

. A argumentação na interação. Coimbra: Grácio Editor, 2016.

PERELMAN, Chaïm. Le Champ de L'Argumentation. Bruxelles: Presses Universitaires de Bruxelles, 1970.

PLANTIN, Christian. Dictionnaire de l'argumentation. Une introduction aux études d'argumentation. Université de Lyon: ENS Éditions, 2016.

\section{Forma de citação sugerida}

GRÁCIO, Rui Alexandre. Da argumentação à demonstração: os estreitamentos focais como estratégias de objetivação. EID\&A - Revista Eletrônica de Estudos Integrados em Discurso e Argumentação, llhéus, n. 18, p. 139-150, abr.2019. DOI dx.doi.org/10.17648/eidea-18-2307. 